\title{
C-Reactive Protein as a Therapeutic Target in Age-Related Macular Degeneration
}

\author{
Blanca Molins ${ }^{1 *}$, Sara Romero-Vázquez ${ }^{1}$, Pablo Fuentes-Prior ${ }^{2,3}$, Alfredo Adan ${ }^{1}$ \\ and Andrew D. Dick ${ }^{4,5,6}$
}

\begin{abstract}
1 Institut d'Investigacions Biomèdiques Agustí Pi i Sunyer (IDIBAPS), Hospital Clínic de Barcelona, Barcelona, Spain, ${ }^{2}$ Molecular Bases of Disease, Biomedical Research Institute Sant Pau (IIB Sant Pau), Barcelona, Spain, ${ }^{3}$ Universitat Autònoma de Barcelona, Bellaterra, Spain, ${ }^{4}$ Academic Unit of Ophthalmology, School of Clinical Sciences, University of Bristol, Bristol, United Kingdom, ${ }^{5}$ Academic Unit of Ophthalmology, School of Cellular and Molecular Medicine, University of Bristol, Bristol, United Kingdom, ${ }^{6}$ National Institute for Health Research (NIHR) Biomedical Research Centre at Moorfields Eye Hospital, University College London Institute of Ophthalmology, London, United Kingdom
\end{abstract}

OPEN ACCESS

Edited by:

Junji Yodoi,

Kyoto University, Japan

Reviewed by:

Sermin Genc,

Dokuz Eylül University,

Turkey

Enrico Tombetti,

San Raffaele Hospital

(IRCCS), Italy

*Correspondence:

Blanca Molins

bmolins@clinic.ub.es

Specialty section: This article was submitted to Inflammation,

a section of the journal

Frontiers in Immunology

Received: 15 December 2017 Accepted: 03 April 2018

Published: 19 April 2018

Citation:

Molins B, Romero-Vázquez $S$, Fuentes-Prior P, Adan A and Dick AD

(2018) C-Reactive Protein as a

Therapeutic Target in Age-Related

Macular Degeneration.

Front. Immunol. 9:808.

doi: 10.3389/fimmu.2018.00808
Age-related macular degeneration (AMD), a retinal degenerative disease, is the leading cause of central vision loss among the elderly population in developed countries and an increasing global burden. The major risk is aging, compounded by other environmental factors and association with genetic variants for risk of progression. Although the etiology of AMD is not yet clearly understood, several pathogenic pathways have been proposed, including dysfunction of the retinal pigment epithelium, inflammation, and oxidative stress. The identification of AMD susceptibility genes encoding complement factors and the presence of complement and other inflammatory mediators in drusen, the hallmark deposits of AMD, support the concept that local inflammation and immune-mediated processes play a key role in AMD pathogenesis that may be accelerated through systemic immune activation. In this regard, increased levels of circulating C-reactive protein (CRP) have been associated with higher risk of AMD. Besides being a risk marker for $\mathrm{AMD}, \mathrm{CRP}$ may also play a role in the progression of the disease as it has been identified in drusen, and we have recently found that its monomeric form (mCRP) induces blood retinal barrier disruption in vitro. In this review, we will address recent evidence that links CRP and AMD pathogenesis, which may open new therapeutic opportunities to prevent the progression of AMD.

Keywords: C-reactive protein, macular degeneration, aging, inflammation, retina

\section{INTRODUCTION}

Age-related macular degeneration (AMD) is the primary cause of irreversible vision loss among the aging population worldwide. The disease affects up to 1.75 million individuals alone in the United States, and this number could increase up to 3 million by $2020(1-3)$. Worldwide, the projected number of people with AMD in 2020 is 196 million (95\% CrI 140-261), which increases to 288 million in 2040 (205-399) (4). AMD is a complex, degenerative, and progressive disease involving multiple genetic and environmental factors, which can ultimately result in severe visual loss. The disease-causing molecular mechanisms remain unknown, although inflammatory processes have been implicated by the identification of AMD susceptibility genes encoding complement factors $(5,6)$ and by the presence of complement proteins in drusen, the hallmark deposits associated with 
AMD and other features of immune activation, including inflammasome activation (7-10).

The pathology of AMD is characterized by vision loss due to alterations in the macula, the central zone of the retina. Visual dysfunction in AMD is associated with the degeneration of the outer portion of the retina, the outer blood retinal barrier (oBRB), which includes the retinal pigment epithelium (RPE), the Bruch's membrane, and the choriocapillaris. This is followed (or in some cases preceded) by degeneration of the light-sensing photoreceptor cells supported by the oBRB. Degeneration of the RPE seems to begin with impaired clearance of cellular waste. The initial clinical manifestations of AMD are characterized by the presence of drusen, deposits of extracellular matrix, and pigment that form most commonly within the macula at the choroid-RPE interface. Based on the size and number of drusen, the presence of atrophy, and/or neovascularization, AMD is classified into five stages of increasing severity (11). Early and intermediate AMD are characterized by the presence of small or large drusen and RPE irregularities. Forms of late AMD include geographic atrophy and neovascularization, both of which can lead to severe central visual impairment and legal blindness due to degenerative and neovascular alterations in the macula, respectively $(11,12)$. Although, currently, neovascular AMD can be controlled with antiangiogenic agents that block vascular endothelial growth factor, most treated patients still suffer from visual impairment as they develop fibrosis and atrophy, and more than one-third of them show long-term loss of effect (13). Most concerning is that there is still no approved treatment for geographic atrophy.

Age is the primary risk factor for AMD. Physiological changes that occur with aging may impair cellular function in those at risk of the disease (14). In addition, other genetic and environmental risk factors are associated with AMD, most significantly smoking (15). A variety of complement pathway-associated gene variants, such as complement factor $\mathrm{H}(\mathrm{CFH})(16)$, factor $\mathrm{B}$, and the complement components $\mathrm{C} 2$ and $\mathrm{C} 3$ have associations with AMD pathogenesis (17). Smoking increases the risk of the exudative type of AMD both in females and men $(18,19)$, and there is a direct association between AMD and raised concentration of cholesterol (20). In addition, small increases in the plasma levels of $\mathrm{C}$-reactive protein (CRP) are an additional associated risk factor for AMD (21). Dietary interventions with carotenoids, oral supplementation with high levels of antioxidants and minerals, or high intake of omega-3 fatty acids and fish arguably slow the course of the disease and are implemented clinically to various degrees worldwide $(22,23)$. Light and photosensitization reactions may also play a role in the development of AMD via synthesis of reactive oxygen species, with consequent damage to the RPE and Bruch's membrane (24). Finally, chronic systemic disorders such as atherosclerosis (25), diabetes (26), and cardiovascular diseases (27) contribute to the risk for AMD development.

Although the etiology of AMD in terms of multifactorial risk factors are increasingly well documented, the patho-etiology of how oxidative stress, atherosclerotic-like changes, RPE cell dysfunction, genetic variants, and inflammation/altered tissue immune responses interlink is less well defined (28-30). One notion to enquire further is the influence of systemic immunity or alarming, acute phase responses in the progression of AMD, not dissimilar to dementia (31). In this context, elevated CRP levels are found both in the blood of AMD patients and in the eyes of carriers of a $\mathrm{CFH}$ polymorphism associated to the risk for developing the disease, providing a molecular clue to AMD pathogenesis and to how genetic risk factors may influence its course $(21,32)$. In this review, we summarize the main findings that support the implication of CRP in the pathogenesis of AMD and its connection with aging.

\section{INFLAMMATION AND AMD}

Chronic inflammation is a prolonged condition in which tissue injury and attempts at repair coexist, leading to tissue remodeling and dysfunction. It is the common pathological basis for age-associated diseases such as cardiovascular disease, diabetes, cancer, Alzheimer's disease, but also AMD. A multitude of bodily changes occur with aging that contribute to the initiation and development of inflammation. In particular, the immune system of elderly individuals is characterized by a basal systemic inflammatory state, as increased levels of proinflammatory cytokines and acute phase reactants are observed with aging (33). Local inflammation and immune-mediated processes play a central role in AMD pathogenesis (34-36).

A competent immune system in the eye is necessary to maintain intraocular health. The network of macrophages and microglia along with the RPE and choroidal endothelial cells maintain tissue homeostasis allowing cellular debris removal and pathogen surveillance. Besides the presence of tissue-resident immune cells, inflammatory molecules are constitutively expressed in the subretinal space, meaning that there is a persistent inflammatory state, known as para-inflammation, which deals with danger signals and protects the tissue against over-inflammation and destruction. Proteomic and histochemical analysis of ocular drusen have shown that these deposits contain inflammatory proteins and complement components that mediate local inflammation, such as C5, C9, CRP, amyloid A, fibrinogen, and vitronectin $(7,37,38)$. The complement system is one of the main effectors of the innate immune response. The activation of the complement system culminates in the formation of the membrane attack complex and, potentially, cell lysis. Accumulation of membrane attack complex in the macula increases with aging and in AMD patients compared to age-matched controls (39-42). On the other hand, some diseases that are associated with complement activation have been independently linked to AMD (43), and a number of complement pathway-associated genes have been recognized as important driving factors of AMD pathogenesis. Some of these genetic variants might cause the complement system to be overactive, resulting in a chronic inflammatory condition $(42,44)$. This abnormal inflammatory stimulus adversely affects RPE cells and promotes drusen formation (45). The strongest genetic risk factor for AMD known to date is a common polymorphism in the CFH gene (c.1277T > C, p.Tyr402His); the CFH p.Tyr402His variant (in following termed $\mathrm{CFH}_{\mathrm{H} 402}$ ) increases the risk for AMD approximately twofold to fourfold for heterozygous and fivefold to sevenfold for homozygous individuals $(5,16,46)$.

$\mathrm{FH}$ is a major inhibitor of the alternate complement pathway that regulates complement activation in plasma, host cells, and 
tissue, in particular, at sites of tissue inflammation, following injury or during degeneration (47). The protein is essentially comprised of 20 tandem Sushi domains, also known as short consensus repeat (SCR) or complement control protein modules. The exchanged residue in the $\mathrm{FH}_{\mathrm{H} 402}$ variant is located in domain SCR7, which mediates the binding to CRP, malondialdehyde (MDA), and to cell surfaces through interactions with heparan sulfate (HS) chains $(48,49)$. The "at risk" variant of $\mathrm{FH}$ shows an impaired binding to these ligands, which could result in increased complement activation and chronic local inflammation. MDA is a toxic by-product of lipid peroxidation and Weismann et al. showed that FH binds MDA through SCR7 and protects from oxidative stress. Notably, the "at risk" variant resulted in severely reduced factor-I-mediated C3 cleavage when bound to MDA (50). Regarding HS, the "non-risk" variant of FH can bind to multiple sites on HS chains in BM due to its wide specificity. Instead, the $402 \mathrm{H}$ variant only binds to highly sulphated motifs within HS $(51,52)$. Thus, if insufficient $\mathrm{FH}$ is present in BM, as is the case for the $402 \mathrm{H}$ variant, there will be increased activation of the complement cascade and the release of pro-inflammatory mediators. However, increased inflammation could be also due to the impaired binding of CRP to the FH from the "at risk" variant.

\section{STRUCTURE AND FUNCTION OF CRP}

CRP is the prototypical acute-phase reactant and an active regulator of the innate immune system; CRP levels increase rapidly in response to infection, inflammation, and tissue injury (53). It is a highly conserved protein of the pentraxin family, mainly produced in the liver. Among the multiple functions ascribed to CRP are activation of the classical complement pathway and inactivation of the alternative pathway (53). In plasma, CRP exists as a cyclic, noncovalent pentamer of $125 \mathrm{kDa}$ composed of five identical subunits (pCRP), and which is stabilized by numerous electrostatic and Van-der-Waals interactions $(54,55)$. Native pCRP binds in a $\mathrm{Ca}^{2+}$-dependent manner to phosphocholine (PCh)-containing ligands such as pneumococcal cell wall C-polysaccharide, but also to the surface of necrotic cells and parasites (55-58). Oxidative stress, low $\mathrm{pH}$, and bioactive lipids from activated or damaged cells can dissociate the CRP pentamer into its $23-\mathrm{kDa}$ subunits (59-62). This poorly soluble, tissue-based monomeric form (mCRP) possesses distinct biological functions compared to pCRP $(60,63-67)$. The dissociation mechanism of CRP requires, first, a reversible structural transition within pCRP subunits, but without disrupting the pentameric symmetry $(60,68,69)$. This rapid conversion to the modified form $\left(\mathrm{pCRP}^{*}\right)$ may contribute to acute phase amplification of the inflammatory response. Then, the $\mathrm{pCRP}^{\star} \rightarrow \mathrm{mCRP}$ irreversible transition is likely to occur at sites of persistent chronic inflammation, where the inflammatory microenvironmentcharacterized by acidic conditions, oxidative stress, and presence of bioactive phospholipids-continuously favors dissociation of the pentameric arrangement. MCRP would then effectively trigger proinflammatory responses and regulate complement (68). Indeed, the dissociation of circulating pCRP to mCRP in areas of inflammation has been observed in vivo in a rat model of acute inflammation. Mechanistically, this process is dependent on exposure of lysophosphatidylcholine (LysoPCh), a bioactive lipid that is generated after phospholipase A2 activation on activated cell membranes $(62,70)$.

The crystal structure of native pCRP in complex with PCh shows how large PCh-containing ligands may be specifically bound by CRP and offers clues to the mechanism of mCRP formation (54). The PCh ligand-binding site is located in a groove of a $\beta$-sheet on the so-called "B face" of the pentamer (Figure 1). Multipoint attachment of this planar face of the CRP molecule to a PCh-bearing surface would leave available, on the opposite A face, the recognition sites for complement C1q. In the absence of $\mathrm{Ca}^{2+}$, residues 140-150 form a loop that projects away from the body of each CRP subunit exposing a normally hidden proteolysis site. Cleavage at this site facilitates that individual CRP subunits move apart, thus exposing a neoepitope (residues 199-206, colored yellow in Figure 1C) that is recognized by antimCRP-specific antibodies (9C9 or 3H12) $(68,71)$. The globular head of $\mathrm{Clq}$ is then able to insert itself into the inner annular void of $\mathrm{pCRP}^{\star}$ (the relaxed conformation) forcing the subunits further apart (noteworthy, C1q is unable to bind to the "strained" pCRP conformation) (68). Finally, the CRP subunits might dissociate, likely accompanied by partial unfolding to generate the mCRP form $(72,73)$. This process would enable CRP to target physiologically and/or pathologically significant complement activation.

\section{MOLECULAR CHANGES IN THE OBRB IN AMD: INTERACTION BETWEEN CRP AND FH}

The fact that patients with AMD and individuals with the $\mathrm{CFH}_{\mathrm{H} 402}$ variant show increased systemic and local levels of CRP, respectively, provides a molecular hint on the pathogenesis of AMD. AMD lesion formation has been proposed to share mechanisms with atherosclerotic plaque formation, which is initiated with low-density lipoprotein retention within the arterial wall (74). Although a thorough discussion of the cross-connections between CRP and cardiovascular diseases is beyond the scope of this review, it is noteworthy that patients with clinical evidence of atherosclerosis (stroke, coronary, and peripheral artery disease) show modestly but significantly increased CRP levels $(25,75,76)$.

Seddon and coworkers were the first to address the relationship between elevated CRP concentrations and AMD progression. They found a significant increase in circulating CRP levels as the disease progressed, and showed that low-, medium-, and highrisk AMD groups are associated with serum CRP concentrations below 0.5 , between 0.5 and 10.0 , and over $10.0 \mathrm{mg} / \mathrm{L}$, respectively $(21,77,78)$. However, this association has not been universally confirmed (79). A more recent study by the Seddon group shows that high levels of circulating CRP are associated with a higher risk of AMD, regardless of the CFH genotype (80).

Other authors have recently attempted to triangulate the association between plasma concentrations of CRP, four CRP genetic variants reported to influence CRP circulating levels, and the risk of advanced AMD (81). They found that two of the genetic variants do share some association with plasma CRP concentrations. 

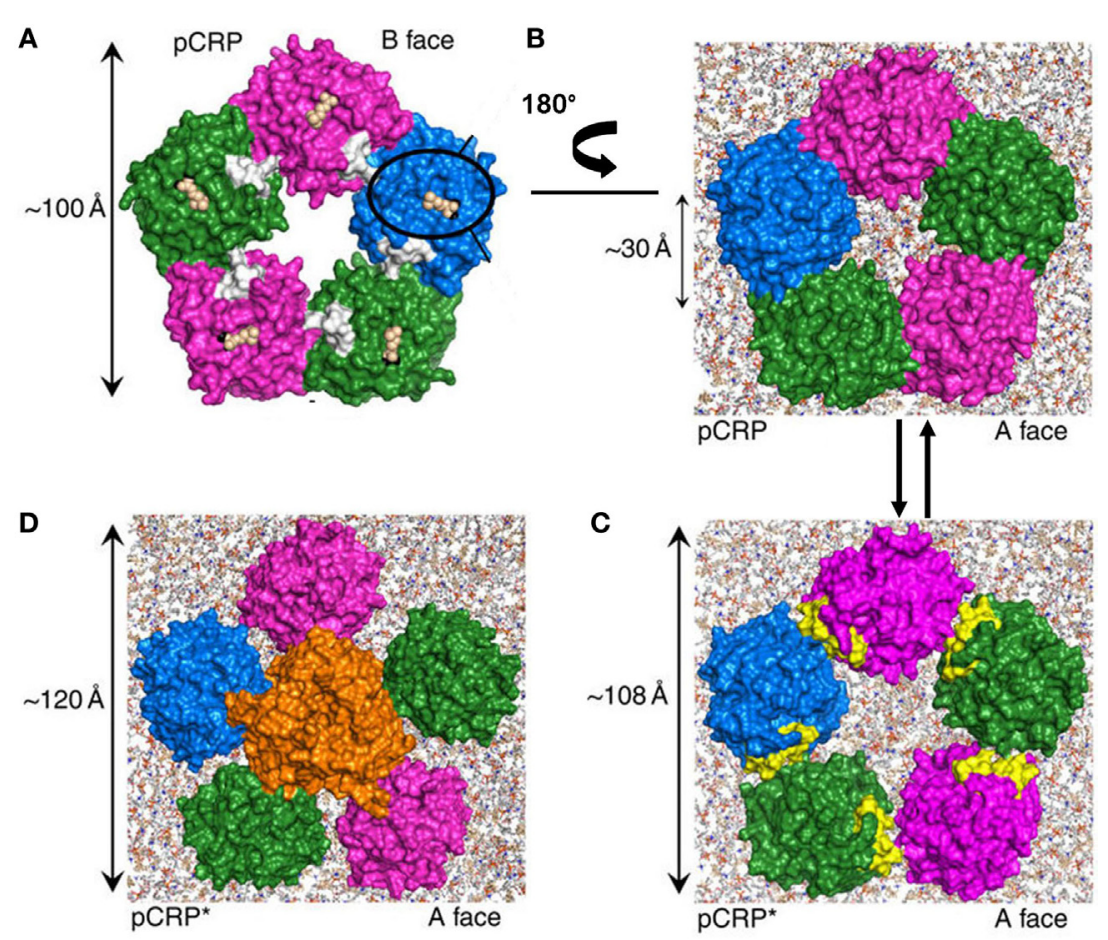

FIGURE 1 | Proposed model of the conversion from the strained to the relaxed conformations of pentameric C-reactive protein (CRP). (A) Solid surface representation of the crystal structure of human CRP in its "strained" conformation (pCRP) bound to phosphocholine (PCh) (PDB entry 1B09) (54). The view shown is from the membrane binding "B face" of pCRP. The individual subunits are represented color-coded, with PCh (cream spheres) and Ca ${ }^{2+}$ ions (black spheres) occupying the ligand binding site on each subunit. (B) Modeled interaction of pCRP with a phospholipid bilayer. View is from "above," looking down onto the pCRP "A face." Each pCRP subunit can independently bind to a PCh head group of the bilayer. Exposure to lysoPCh triggers reversible conversion of pCRP to $\mathrm{pCRP}^{\star}$. (C) Pentameric pCRP*, same view as in (B). As the individual CRP subunits move apart, a neoepitope (colored yellow) is exposed. (D) The globular head of $\mathrm{C} 1 \mathrm{q}$ inserts itself into the inner annular void of $\mathrm{pCRP}^{\star}$ forcing the subunits further apart [adapted from Braig et al. (68)].

However, none of the four variants was significantly associated with the risk of AMD. Their findings have important implications for our understanding of the pathophysiology of AMD, in particular, for the distinct roles played by local and systemic inflammation in this regard. However, it must be considered that other factors such as C3 genotype and smoking strongly affect circulating CRP levels. Thus, these results do not preclude a direct link between AMD pathophysiology through complement activation and chronic inflammation, and plasma CRP concentrations might still be useful as an AMD biomarker. Important differences exist between systemic inflammation and the local inflammatory macular tissue microenvironment.

Since CFH risk haplotypes are associated with increased complement activation in human macular tissue (82) but not in the circulation $(83,84)$, it is important to determine the localization and abundance of both CRP and FH in the extra-macular choroid of individuals homozygous for the high-risk $\mathrm{CFH}_{\mathrm{H} 402}$ genotype, as compared to those homozygous for the low-risk $\mathrm{CFH}_{\mathrm{Y} 402}$ variant. This investigation, reported by Johnson and colleagues, showed that the localization and abundance of $\mathrm{FH}$ do not differ between $\mathrm{CFH}$ genotypes (32). However, choroidal immuno-staining of $\mathrm{CRP}$ was significantly higher in the $\mathrm{CFH}_{\mathrm{H} 402}$ eyes compared to the $\mathrm{CFH}_{\mathrm{Y} 402}$ eyes. Interestingly, these differences between the $\mathrm{CFH}$ homozygotes were independent of AMD status. Because the high-risk allele affects binding of FH to CRP (85), deficient FH binding could potentially increase the pro-inflammatory activity of CRP in choroidal tissue, contributing to AMD pathogenesis. Also along these lines, Bhutto and colleagues have reported distinct patterns of localization for $\mathrm{FH}$ and CRP in the aging eye. Most notably, these authors found an inverse relationship between CRP and FH levels in macular tissue from patients with advanced AMD as compared to age-matched control individuals (86). In AMD patients, Bruch's membrane, drusen, and choroidal vessel walls all showed increased labeling of CRP and decreased labeling of FH compared to controls. These findings support the idea that the macula of AMD patients has an increased inflammatory microenvironment with decreased capacity for complement inhibition.

Although FH is known to bind CRP, there was certain controversy regarding the relevance of the monomeric and pentameric forms in this regard. For instance, two separate binding sites for pCRP were located on domains SCR4-6 and SCR16-20, respectively (49). On the other hand, FH showed strong binding to denatured, monomeric CRP, rather than to the native multimeric form $(87,88)$. We have recently shown that mCRP, but not the pentameric form, contributes to oBRB disruption in vitro (89). The functional integrity of the RPE, critical for the maintenance of the specialized environment of the neural retina, is dependent 
on the structures of tight junctions. Exposure to mCRP, but not pCRP, significantly increased the paracellular permeability of the RPE compared with that of untreated cells, suggesting that mCRP could compromise the barrier function of the RPE monolayer. Notably, mCRP was also able to disturb the expression and distribution of the TJ proteins, ZO-1, and occludin. In another study, we also showed that mCRP confers a proinflammatory phenotype to RPE cells as it increases production of the proinflammatory cytokines IL-8 and CCL2 (Figure 2) (90). The mCRP-induced pro-inflammatory phenotype was further demonstrated by the significantly increased rates of peripheral blood mononuclear cells migration treated with conditioned medium from RPE cells after being exposed to mCRP, but not with conditioned media from either untreated cells or from cells exposed to pCRP. The oBRB disruption induced by mCRP could conceivably permit passage of inflammatory cells into the retina, further contributing to chronic inflammation and accelerating tissue damage.

Moreover, we also showed that the "non-risk" FH variant $\left(\mathrm{CFH}_{\mathrm{Y} 402}\right)$ can effectively bind to mCRP to dampen mCRP proinflammatory activity. Notably, FH from AMD patients carrying the risk polymorphism for AMD shows an impaired binding to $\mathrm{mCRP}$ and, therefore, its proinflammatory effects remain unrestrained (Figure 2) (90). In line with and highlighting our findings, Chirco et al. have recently shown that $\mathrm{MCRP}$ is the more abundant form of CRP in human RPE-choroid, and that mCRP levels are elevated in individuals with the high-risk CFH genotype (91), which could thus sustain chronic inflammation contributing to the progression of AMD in $\mathrm{CFH}_{\mathrm{H} 402}$ individuals. Moreover, pro-inflammatory mCRP significantly affects endothelial cell phenotypes, suggesting a role for mCRP in choroidal vascular dysfunction in AMD as well.

It is also interesting to note that, in our cohort of AMD patients, those carrying the risk variant of $\mathrm{CFH}$ had significantly higher levels of systemic IL-8 and CRP than healthy subjects carrying the non-risk allele (90). Further, the levels of these proteins were positively correlated in AMD patients homozygous for the risk $\mathrm{CFH}_{\mathrm{H} 402}$ variant. These results are in conflict with previous studies showing that $\mathrm{CRP}$ levels and the $\mathrm{CFH}_{\mathrm{H} 402}$ polymorphism were independent risk factors for AMD (80). We observed differences in circulating CRP concentrations between subjects carrying the different $\mathrm{CFH}$ variants, albeit in a smaller population. Our results

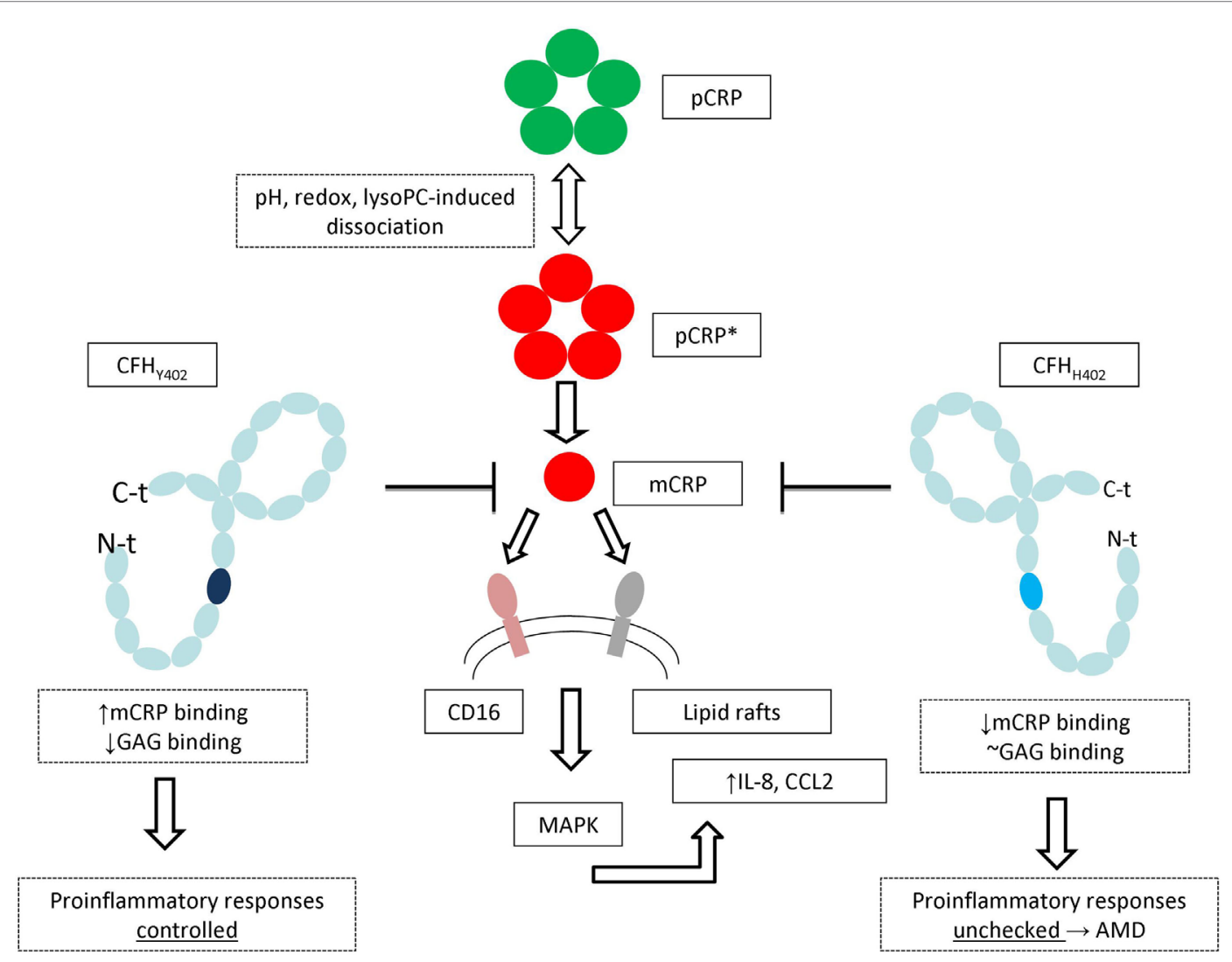

FIGURE 2 | A unified mechanism of mCRP-induced proinflammatory responses and the role of the CFH p.Tyr402His polymorphism in age-related macular degeneration (AMD). Generation of mCRP is accelerated in vivo under inflammatory conditions by bioactive lipids such as lysophosphatidylcholine (lysoPC) exposed on the surface of microparticles, activated or damaged cells. mCRP is recognized on the cell surface, leading to activation of MAPK pathways and ultimately enhances expression of proinflammatory cytokines and disrupts the outer blood retinal barrier. Binding of $\mathrm{FH}$ to $\mathrm{mCRP}$ attenuates this inflammatory response, but the $\mathrm{FH}_{\mathrm{H} 402}$ variant is less effective in this regard, both because of its altered binding to glycosaminoglycans (52), but, in particular, due to its markedly lower affinity for mCRP. The unchecked inflammatory response leads eventually to progression of AMD and vision loss [figure adapted from Molins et al. (90)]. 
might explain the previously reported higher risk of AMD within genetically susceptible individuals when CRP concentrations are high (80). We hypothesize that higher levels of circulating CRP could derive in higher mCRP concentrations in microenvironments that favor dissociation, such as inflammatory or apoptotic conditions, which in the case of patients carrying the $\mathrm{CFH}_{\mathrm{H} 402}$ risk variant would further cause unchecked inflammation. However, it is unclear where, when, and how mCRP dissociates within the oBRB. mCRP could either dissociate distantly in activated endothelium or locally within the RPE. Unchecked mCRP activity may sustain chronic inflammation thus favoring AMD progression. Whether this provokes disease or not requires validation, but this process alone may not be sufficient to explain all the immune-related changes we observe in AMD and, therefore, further research is warranted.

\section{TARGETING MONOMERIC CRP IN AMD}

The recent findings from us and others discussed above reinforce the importance of mCRP in chronic inflammation and point to the pCRP dissociation process and/or mCRP itself as novel therapeutic targets for AMD. Indeed, therapies associated with a reduction in systemic CRP levels are successfully used in other chronic inflammatory diseases such as atherosclerosis, where CRP is an important player (76). However, given that CRP may have a more important role in the macular tissue, it might be more appropriate to target local CRP for AMD treatment. Blocking the dissociation of pCRP with 1,6-bis-PCh, a compound that stabilizes CRP in a decameric form, abolished the proinflammatory effects of mCRP in vivo (62). Restrictively, 1,6-bis PCh is not suitable for clinical purposes due to its pharmacokinetics and its low affinity for pCRP (150 nM) (62). Thus, a more potent drug with higher oral bioavailability, higher affinity for PCRP, and prolonged half-time needs to be designed to efficiently target the pCRP dissociation process as an innovative therapeutic strategy. Blocking LysoPCh formation with PLA2 inhibitors may be another interesting

\section{REFERENCES}

1. Klein R, Peto T, Bird A, Vannewkirk MR. The epidemiology of age-related macular degeneration. Am J Ophthalmol (2004) 137(3):486-95. doi:10.1016/ S0002-9394(04)00052-2

2. van Leeuwen R, Klaver CC, Vingerling JR, Hofman A, de Jong PT. Epidemiology of age-related maculopathy: a review. Eur J Epidemiol (2003) 18(9):845-54. doi:10.1023/A:1025643303914

3. Klein R, Chou CF, Klein BE, Zhang X, Meuer SM, Saaddine JB. Prevalence of age-related macular degeneration in the US population. Arch Ophthalmol (2011) 129(1):75-80. doi:10.1001/archophthalmol.2010.318

4. Wong WL, Su X, Li X, Cheung CM, Klein R, Cheng CY, et al. Global prevalence of age-related macular degeneration and disease burden projection for 2020 and 2040: a systematic review and meta-analysis. Lancet Glob Health (2014) 2(2):e106-16. doi:10.1016/S2214-109X(13)70145-1

5. Edwards AO, Ritter R III, Abel KJ, Manning A, Panhuysen C, Farrer LA. Complement factor $\mathrm{H}$ polymorphism and age-related macular degeneration. Science (2005) 308(5720):421-4. doi:10.1126/science.1110189

6. Fritsche LG, Igl W, Bailey JN, Grassmann F, Sengupta S, Bragg-Gresham JL, et al. A large genome-wide association study of age-related macular degeneration highlights contributions of rare and common variants. Nat Genet (2016) 48(2):134-43. doi:10.1038/ng.3448 approach to inhibit pCRP dissociation. Alternatively, therapeutic approaches aimed to enhance FH-mCRP binding could be developed to block mCRP proinflammatory activities, thus preventing the progression of AMD.

\section{CONCLUSION}

The reduced ability to control the balance between pro- and anti-inflammatory signals associated with aging might promote a switch to chronic inflammation in the macular tissue. This scenario could then favor CRP dissociation and mCRP accumulation further fueling chronic inflammation and tissue damage, especially in those patients with the "risk" $\mathrm{FH}$ variant, $\mathrm{CFH}_{\mathrm{H} 402}$, where $\mathrm{FH}$ is unable to dampen $\mathrm{mCRP}$ proinflammatory activity and to localize to HS in Bruch's membrane. A combination of poor binding of the $\mathrm{FH} \mathrm{H} 402$ variant to Bruch's membrane and mCRP, combined with aging associated processes such HS loss and an increased proinflammatory environment, may eventually result in complement activation, persistent mCRP-induced inflammation, and thereby contribute to AMD progression. Future research is warranted to confirm the contribution of mCRP to disease etiology and progression, and eventually to test the therapeutic potential of compounds that either prevent CRP dissociation or stimulate $\mathrm{FH}$ binding to mCRP.

\section{AUTHOR CONTRIBUTIONS}

$\mathrm{BM}, \mathrm{PF}-\mathrm{P}, \mathrm{SR}-\mathrm{V}, \mathrm{AA}$, and $\mathrm{AD}$ contributed to the design of the project and manuscript preparation, and all authors reviewed the manuscript.

\section{FUNDING}

This work was supported by the Ministry of Science and Innovation of Spain, "Instituto de Salud Carlos III," "Fondo de Investigación Sanitaria” (RD16/0008).

7. Mullins RF, Russell SR, Anderson DH, Hageman GS. Drusen associated with aging and age-related macular degeneration contain proteins common to extracellular deposits associated with atherosclerosis, elastosis, amyloidosis, and dense deposit disease. FASEB J (2000) 14(7):835-46. doi:10.1096/ fasebj.14.7.835

8. Ambati J, Atkinson JP, Gelfand BD. Immunology of age-related macular degeneration. Nat Rev Immunol (2013) 13(6):438-51. doi:10.1038/nri3459

9. Lambert NG, ElShelmani H, Singh MK, Mansergh FC, Wride MA, Padilla M, et al. Risk factors and biomarkers of age-related macular degeneration. Prog Retin Eye Res (2016) 54:64-102. doi:10.1016/j.preteyeres.2016.04.003

10. Whitcup SM, Sodhi A, Atkinson JP, Holers VM, Sinha D, Rohrer B, et al. The role of the immune response in age-related macular degeneration. Int J Inflam (2013) 2013:348092. doi:10.1155/2013/348092

11. Ferris FL III, Wilkinson CP, Bird A, Chakravarthy U, Chew E, Csaky K, et al. Clinical classification of age-related macular degeneration. Ophthalmology (2013) 120(4):844-51. doi:10.1016/j.ophtha.2012.10.036

12. Age-Related Eye Disease Study Research Group. The age-related eye disease study system for classifying age-related macular degeneration from stereoscopic color fundus photographs: the age-related eye disease study report number 6 . Am J Ophthalmol (2001) 132(5):668-81. doi:10.1016/S0002-9394(01)01218-1

13. Rofagha S, Bhisitkul RB, Boyer DS, Sadda SR, Zhang K. Seven-year outcomes in ranibizumab-treated patients in ANCHOR, MARINA, and 
HORIZON: a multicenter cohort study (SEVEN-UP). Ophthalmology (2013) 120(11):2292-9. doi:10.1016/j.ophtha.2013.03.046

14. Demontis F, Piccirillo R, Goldberg AL, Perrimon N. Mechanisms of skeletal muscle aging: insights from Drosophila and mammalian models. Dis Model Mech (2013) 6(6):1339-52. doi:10.1242/dmm.012559

15. Khan JC, Thurlby DA, Shahid H, Clayton DG, Yates JR, Bradley M, et al. Smoking and age related macular degeneration: the number of pack years of cigarette smoking is a major determinant of risk for both geographic atrophy and choroidal neovascularisation. Br JOphthalmol (2006) 90(1):75-80. doi:10.1136/bjo.2005.073643

16. Klein RJ, Zeiss C, Chew EY, Tsai JY, Sackler RS, Haynes C, et al. Complement factor $\mathrm{H}$ polymorphism in age-related macular degeneration. Science (2005) 308(5720):385-9. doi:10.1126/science.1109557

17. Yates JR, Sepp T, Matharu BK, Khan JC, Thurlby DA, Shahid H, et al. Complement $\mathrm{C} 3$ variant and the risk of age-related macular degeneration. N Engl J Med (2007) 357(6):553-61. doi:10.1056/NEJMoa072618

18. Christen WG, Glynn RJ, Manson JE, Ajani UA, Buring JE. A prospective study of cigarette smoking and risk of age-related macular degeneration in men. JAMA (1996) 276(14):1147-51. doi:10.1001/jama.1996.03540140035023

19. Seddon JM, Willett WC, Speizer FE, Hankinson SE. A prospective study of cigarette smoking and age-related macular degeneration in women. JAMA (1996) 276(14):1141-6. doi:10.1001/jama.1996.03540140029022

20. Tomany SC, Wang JJ, Van Leeuwen R, Klein R, Mitchell P, Vingerling JR, et al. Risk factors for incident age-related macular degeneration: pooled findings from 3 continents. Ophthalmology (2004) 111(7):1280-7. doi:10.1016/j.ophtha. 2003.11.010

21. Seddon JM, Gensler G, Milton RC, Klein ML, Rifai N. Association between C-reactive protein and age-related macular degeneration. JAMA (2004) 291(6):704-10. doi:10.1001/jama.291.6.704

22. Age-Related Eye Disease Study Research Group. A randomized, placebocontrolled, clinical trial of high-dose supplementation with vitamins $\mathrm{C}$ and $\mathrm{E}$ and beta carotene for age-related cataract and vision loss: AREDS report no. 9. Arch Ophthalmol (2001) 119(10):1439-52. doi:10.1001/archopht.119.10.1439

23. SanGiovanni JP, Chew EY, Clemons TE, Davis MD, Ferris FL III, Gensler GR, et al. The relationship of dietary lipid intake and age-related macular degeneration in a case-control study: AREDS report no. 20. Arch Ophthalmol (2007) 125(5):671-9. doi:10.1001/archopht.125.5.671

24. Winkler BS, Boulton ME, Gottsch JD, Sternberg P. Oxidative damage and age-related macular degeneration. Mol Vis (1999) 5:32.

25. Vine AK, Stader J, Branham K, Musch DC, Swaroop A. Biomarkers of cardiovascular disease as risk factors for age-related macular degeneration. Ophthalmology (2005) 112(12):2076-80. doi:10.1016/j.ophtha.2005.07.004

26. Choi JK, Lym YL, Moon JW, Shin HJ, Cho B. Diabetes mellitus and early age-related macular degeneration. Arch Ophthalmol (2011) 129(2):196-9. doi:10.1001/archophthalmol.2010.355

27. Tan JS, Mitchell P, Smith W, Wang JJ. Cardiovascular risk factors and the long-term incidence of age-related macular degeneration: the Blue Mountains Eye Study. Ophthalmology (2007) 114(6):1143-50. doi:10.1016/j. ophtha.2006.09.033

28. Miller JW. Age-related macular degeneration revisited - piecing the puzzle: the LXIX Edward Jackson memorial lecture. Am JOphthalmol (2013) 155(1):1-35.e13. doi:10.1016/j.ajo.2012.10.018

29. Nussenblatt RB, Lee RW, Chew E, Wei L, Liu B, Sen HN, et al. Immune responses in age-related macular degeneration and a possible long-term therapeutic strategy for prevention. Am J Ophthalmol (2014) 158(1):5-11.e2. doi:10.1016/j.ajo.2014.03.014

30. Zarbin MA. Current concepts in the pathogenesis of age-related macular degeneration. Arch Ophthalmol (2004) 122(4):598-614. doi:10.1001/archopht. 122.4.598

31. Holmes C, Cunningham C, Zotova E, Woolford J, Dean C, Kerr S, et al. Systemic inflammation and disease progression in Alzheimer disease. Neurology (2009) 73(10):768-74. doi:10.1212/WNL.0b013e3181b6bb95

32. Johnson PT, Betts KE, Radeke MJ, Hageman GS, Anderson DH, Johnson LV. Individuals homozygous for the age-related macular degeneration riskconferring variant of complement factor $\mathrm{H}$ have elevated levels of CRP in the choroid. Proc Natl Acad Sci U S A (2006) 103(46):17456-61. doi:10.1073/ pnas. 0606234103

33. Shaw AC, Goldstein DR, Montgomery RR. Age-dependent dysregulation of innate immunity. Nat Rev Immunol (2013) 13(12):875-87. doi:10.1038/nri3547
34. Donoso LA, Kim D, Frost A, Callahan A, Hageman G. The role of inflammation in the pathogenesis of age-related macular degeneration. Surv Ophthalmol (2006) 51(2):137-52. doi:10.1016/j.survophthal.2005.12.001

35. Dick AD. Doyne lecture 2016: intraocular health and the many faces of inflammation. Eye (Lond) (2017) 31(1):87-96. doi:10.1038/eye.2016.177

36. Kim Y, Tarallo V, Kerur N, Yasuma T, Gelfand BD, Bastos-Carvalho A, et al. DICER1/Alu RNA dysmetabolism induces caspase-8-mediated cell death in age-related macular degeneration. Proc Natl Acad Sci U S A (2014) 111(45):16082-7. doi:10.1073/pnas.1403814111

37. Anderson DH, Mullins RF, Hageman GS, Johnson LV. A role for local inflammation in the formation of drusen in the aging eye. Am J Ophthalmol (2002) 134(3):411-31. doi:10.1016/S0002-9394(02)01624-0

38. Crabb JW, Miyagi M, Gu X, Shadrach K, West KA, Sakaguchi H, et al. Drusen proteome analysis: an approach to the etiology of age-related macular degeneration. Proc Natl Acad Sci U S A (2002) 99(23):14682-7. doi:10.1073/ pnas. 222551899

39. Mullins RF, Schoo DP, Sohn EH, Flamme-Wiese MJ, Workamelahu G, Johnston RM, et al. The membrane attack complex in aging human choriocapillaris: relationship to macular degeneration and choroidal thinning. Am J Pathol (2014) 184(11):3142-53. doi:10.1016/j.ajpath.2014.07.017

40. Seth A, Cui J, To E, Kwee M, Matsubara J. Complement-associated deposits in the human retina. Invest Ophthalmol Vis Sci (2008) 49(2):743-50. doi:10.1167/ iovs. 07-1072

41. Skeie JM, Fingert JH, Russell SR, Stone EM, Mullins RF. Complement component $\mathrm{C} 5$ a activates ICAM- 1 expression on human choroidal endothelial cells. Invest Ophthalmol Vis Sci (2010) 51(10):5336-42. doi:10.1167/iovs. 10-5322

42. Hageman GS, Anderson DH, Johnson LV, Hancox LS, Taiber AJ, Hardisty LI, et al. A common haplotype in the complement regulatory gene factor $\mathrm{H}$ (HF1/ $\mathrm{CFH}$ ) predisposes individuals to age-related macular degeneration. Proc Natl Acad Sci U S A (2005) 102(20):7227-32. doi:10.1073/pnas.0501536102

43. Nitsch D, Douglas I, Smeeth L, Fletcher A. Age-related macular degeneration and complement activation-related diseases: a population-based case-control study. Ophthalmology (2008) 115(11):1904-10. doi:10.1016/j. ophtha.2008.06.035

44. Kawa MP, Machalinska A, Roginska D, Machalinski B. Complement system in pathogenesis of AMD: dual player in degeneration and protection of retinal tissue. J Immunol Res (2014) 2014:483960. doi:10.1155/2014/483960

45. Jakobsdottir J, Conley YP, Weeks DE, Ferrell RE, Gorin MB. C2 and CFB genes in age-related maculopathy and joint action with CFH and LOC387715 genes. PLoS One (2008) 3(5):e2199. doi:10.1371/journal.pone.0002199

46. Haines JL, Hauser MA, Schmidt S, Scott WK, Olson LM, Gallins P, et al. Complement factor $\mathrm{H}$ variant increases the risk of age-related macular degeneration. Science (2005) 308(5720):419-21. doi:10.1126/science.1110359

47. Langford-Smith A, Keenan TD, Clark SJ, Bishop PN, Day AJ. The role of complement in age-related macular degeneration: heparan sulphate, a ZIP code for complement factor H? J Innate Immun (2014) 6(4):407-16. doi:10.1159/ 000356513

48. Giannakis E, Jokiranta TS, Male DA, Ranganathan S, Ormsby RJ, Fischetti VA, et al. A common site within factor H SCR 7 responsible for binding heparin, C-reactive protein and streptococcal M protein. Eur J Immunol (2003) 33(4):962-9. doi:10.1002/eji.200323541

49. Okemefuna AI, Nan R, Miller A, Gor J, Perkins SJ. Complement factor H binds at two independent sites to $\mathrm{C}$-reactive protein in acute phase concentrations. J Biol Chem (2010) 285(2):1053-65. doi:10.1074/jbc.M109.044529

50. Weismann D, Hartvigsen K, Lauer N, Bennett KL, Scholl HP, Charbel Issa P, et al. Complement factor $\mathrm{H}$ binds malondialdehyde epitopes and protects from oxidative stress. Nature (2011) 478(7367):76-81. doi:10.1038/nature10449

51. Clark SJ, Schmidt CQ, White AM, Hakobyan S, Morgan BP, Bishop PN. Identification of factor $\mathrm{H}$-like protein 1 as the predominant complement regulator in Bruch's membrane: implications for age-related macular degeneration. J Immunol (2014) 193(10):4962-70. doi:10.4049/jimmunol. 1401613

52. Clark SJ, Perveen R, Hakobyan S, Morgan BP, Sim RB, Bishop PN, et al. Impaired binding of the age-related macular degeneration-associated complement factor $\mathrm{H} 402 \mathrm{H}$ allotype to Bruch's membrane in human retina. J Biol Chem (2010) 285(39):30192-202. doi:10.1074/jbc.M110.103986

53. Black S, Kushner I, Samols D. C-reactive protein. J Biol Chem (2004) 279(47):48487-90. doi:10.1074/jbc.R400025200 
54. Thompson D, Pepys MB, Wood SP. The physiological structure of human C-reactive protein and its complex with phosphocholine. Structure (1999) 7(2):169-77. doi:10.1016/S0969-2126(99)80023-9

55. Volanakis JE, Kaplan MH. Specificity of C-reactive protein for choline phosphate residues of pneumococcal C-polysaccharide. Proc Soc Exp Biol Med (1971) 136(2):612-4. doi:10.3181/00379727-136-35323

56. Volanakis JE, Wirtz KW. Interaction of C-reactive protein with artificial phosphatidylcholine bilayers. Nature (1979) 281(5727):155-7. doi:10.1038/ $281155 \mathrm{a} 0$

57. Chang MK, Binder CJ, Torzewski M, Witztum JL. C-reactive protein binds to both oxidized LDL and apoptotic cells through recognition of a common ligand: phosphorylcholine of oxidized phospholipids. Proc Natl Acad Sci U S A (2002) 99(20):13043-8. doi:10.1073/pnas.192399699

58. Ahmed UK, Maller NC, Iqbal AJ, Al-Riyami L, Harnett W, Raynes JG. The carbohydrate-linked phosphorylcholine of the parasitic nematode product ES-62 modulates complement activation. J Biol Chem (2016) 291(22): 11939-53. doi:10.1074/jbc.M115.702746

59. Eisenhardt SU, Habersberger J, Murphy A, Chen YC, Woollard KJ, Bassler N, et al. Dissociation of pentameric to monomeric C-reactive protein on activated platelets localizes inflammation to atherosclerotic plaques. Circ Res (2009) 105(2):128-37. doi:10.1161/CIRCRESAHA.108.190611

60. Ji SR, Wu Y, Zhu L, Potempa LA, Sheng FL, Lu W, et al. Cell membranes and liposomes dissociate $\mathrm{C}$-reactive protein (CRP) to form a new, biologically active structural intermediate: $\mathrm{mCRP}(\mathrm{m})$. FASEB J (2007) 21(1):284-94. doi:10.1096/f.06-6722com

61. Lauer N, Mihlan M, Hartmann A, Schlötzer-Schrehardt U, Keilhauer C, Scholl HP, et al. Complement regulation at necrotic cell lesions is impaired by the age-related macular degeneration-associated factor-H His402 risk variant. J Immunol (2011) 187(8):4374-83. doi:10.4049/jimmunol.1002488

62. Thiele JR, Habersberger J, Braig D, Schmidt Y, Goerendt K, Maurer V, et al. Dissociation of pentameric to monomeric C-reactive protein localizes and aggravates inflammation: in vivo proof of a powerful proinflammatory mechanism and a new anti-inflammatory strategy. Circulation (2014) 130(1): 35-50. doi:10.1161/CIRCULATIONAHA.113.007124

63. Khreiss T, József L, Hossain S, Chan JS, Potempa LA, Filep JG. Loss of pentameric symmetry of $\mathrm{C}$-reactive protein is associated with delayed apoptosis of human neutrophils. J Biol Chem (2002) 277(43):40775-81. doi:10.1074/jbc. M205378200

64. Khreiss T, Jozsef L, Potempa LA, Filep JG. Conformational rearrangement in C-reactive protein is required for proinflammatory actions on human endothelial cells. Circulation (2004) 109(16):2016-22. doi:10.1161/01. CIR.0000125527.41598.68

65. Khreiss T, Jozsef L, Potempa LA, Filep JG. Loss of pentameric symmetry in C-reactive protein induces interleukin-8 secretion through peroxynitrite signaling in human neutrophils. Circ Res (2005) 97(7):690-7. doi:10.1161/01. RES.0000183881.11739.CB

66. Molins B, Pena E, de la Torre R, Badimon L. Monomeric CRP is prothrombotic and dissociates from circulating pentameric CRP on adhered activated platelets under flow. Cardiovasc Res (2011). doi:10.1093/cvr/cvr226

67. Molins B, Peña E, Vilahur G, Mendieta C, Slevin M, Badimon L. C-reactive protein isoforms differ in their effects on thrombus growth. Arterioscler Thromb Vasc Biol (2008) 28(12):2239-46. doi:10.1161/ATVBAHA.108.174359

68. Braig D, Nero TL, Koch HG, Kaiser B, Wang X, Thiele JR, et al. Transitional changes in the CRP structure lead to the exposure of proinflammatory binding sites. Nat Commun (2017) 8:14188. doi:10.1038/ncomms14188

69. Singh SK, Thirumalai A, Pathak A, Ngwa DN, Agrawal A. Functional transformation of C-reactive protein by hydrogen peroxide. J Biol Chem (2017) 292(8):3129-36. doi:10.1074/jbc.M116.773176

70. Habersberger J, Strang F, Scheichl A, Htun N, Bassler N, Merivirta RM, et al. Circulating microparticles generate and transport monomeric C-reactive protein in patients with myocardial infarction. Cardiovasc Res (2012) 96(1):64-72. doi:10.1093/cvr/cvs237

71. Potempa LA, Yao ZY, Ji SR, Filep JG, Wu Y. Solubilization and purification of recombinant modified C-reactive protein from inclusion bodies using reversible anhydride modification. Biophys Rep (2015) 1:18-33. doi:10.1007/ s41048-015-0003-2

72. Christopeit T, Gossas T, Danielson UH. Characterization of Ca2+ and phosphocholine interactions with $\mathrm{C}$-reactive protein using a surface plasmon resonance biosensor. Anal Biochem (2009) 391(1):39-44. doi:10.1016/j.ab.2009.04.037
73. Mikolajek H, Kolstoe SE, Pye VE, Mangione P, Pepys MB, Wood SP. Structural basis of ligand specificity in the human pentraxins, C-reactive protein and serum amyloid P component. J Mol Recognit (2011) 24(2):371-7. doi:10.1002/ jmr.1090

74. Curcio CA, Johnson M, Huang JD, Rudolf M. Aging, age-related macular degeneration, and the response-to-retention of apolipoprotein B-containing lipoproteins. Prog Retin Eye Res (2009) 28(6):393-422. doi:10.1016/j. preteyeres.2009.08.001

75. Ridker PM, Rifai N, Rose L, Buring JE, Cook NR. Comparison of C-reactive protein and low-density lipoprotein cholesterol levels in the prediction of first cardiovascular events. N Engl J Med (2002) 347(20):1557-65. doi:10.1056/ NEJMoa021993

76. Ridker PM, Danielson E, Fonseca FA, Genest J, Gotto AM Jr, Kastelein JJ, et al. Rosuvastatin to prevent vascular events in men and women with elevated C-reactive protein. N Engl J Med (2008) 359(21):2195-207. doi:10.1056/ NEJMoa0807646

77. Seddon JM, Cote J, Page WF, Aggen SH, Neale MC. The US twin study of age-related macular degeneration: relative roles of genetic and environmental influences. Arch Ophthalmol (2005) 123(3):321-7. doi:10.1001/ archopht.123.3.321

78. Seddon JM, Gensler G, Klein ML, Milton RC. C-reactive protein and homocysteine are associated with dietary and behavioral risk factors for agerelated macular degeneration. Nutrition (2006) 22(4):441-3. doi:10.1016/j. nut.2005.12.004

79. McGwin G, Hall TA, Xie A, Owsley C. The relation between C reactive protein and age related macular degeneration in the Cardiovascular Health Study. Br J Ophthalmol (2005) 89(9):1166-70. doi:10.1136/bjo.2005.067397

80. Seddon JM, Gensler G, Rosner B. C-reactive protein and CFH, ARMS2/HTRA1 gene variants are independently associated with risk of macular degeneration. Ophthalmology (2010) 117(8):1560-6. doi:10.1016/j.ophtha.2009.11.020

81. Cipriani V, Hogg RE, Sofat R, Moore AT, Webster AR, Yates JRW, et al. Association of C-reactive protein genetic polymorphisms with late age-related macular degeneration. JAMA Ophthalmol (2017) 135(9):909-16. doi:10.1001/ jamaophthalmol.2017.2191

82. Keenan TD, Toso M, Pappas C, Nichols L, Bishop PN, Hageman GS. Assessment of proteins associated with complement activation and inflammation in maculae of human donors homozygous risk at chromosome $1 \mathrm{CFH}-$ to-F13B. Invest Ophthalmol Vis Sci (2015) 56(8):4870-9. doi:10.1167/iovs.15-17009

83. Ristau T, Paun C, Ersoy L, Hahn M, Lechanteur Y, Hoyng C, et al. Impact of the common genetic associations of age-related macular degeneration upon systemic complement component C3d levels. PLoS One (2014) 9(3):e93459. doi:10.1371/journal.pone.0093459

84. Hecker LA, Edwards AO, Ryu E, Tosakulwong N, Baratz KH, Brown WL, et al. Genetic control of the alternative pathway of complement in humans and age-related macular degeneration. Hum Mol Genet (2010) 19(1):209-15. doi:10.1093/hmg/ddp472

85. Laine M, Jarva H, Seitsonen S, Haapasalo K, Lehtinen MJ, Lindeman N, et al. $\mathrm{Y} 402 \mathrm{H}$ polymorphism of complement factor $\mathrm{H}$ affects binding affinity to C-reactive protein. J Immunol (2007) 178(6):3831-6. doi:10.4049/jimmunol. 178.6.3831

86. Bhutto IA, Baba T, Merges C, Juriasinghani V, McLeod DS, Lutty GA. $\mathrm{C}$-reactive protein and complement factor $\mathrm{H}$ in aged human eyes and eyes with age-related macular degeneration. Br J Ophthalmol (2011) 95(9):1323-30. doi:10.1136/bjo.2010.199216

87. Bíró A, Rovó Z, Papp D, Cervenak L, Varga L, Füst G, et al. Studies on the interactions between C-reactive protein and complement proteins. Immunology (2007) 121(1):40-50. doi:10.1111/j.1365-2567.2007.02535.x

88. Hakobyan S, Harris CL, van den Berg CW, Fernandez-Alonso MC, de Jorge EG, de Cordoba SR, et al. Complement factor $\mathrm{H}$ binds to denatured rather than to native pentameric C-reactive protein. J Biol Chem (2008) 283(45):30451-60. doi:10.1074/jbc.M803648200

89. Molins B, Pascual A, Méndez, Llorenç V, Zarranz-Ventura J, Mesquida M, et al. C-reactive protein isoforms differentially affect outer blood-retinal barrier integrity and function. Am J Physiol Cell Physiol (2017) 312(3):C244-53. doi:10.1152/ajpcell.00057.2016

90. Molins B, Fuentes-Prior P, Adán A, Antón R, Arostegui JI, Yagüe J, et al. Complement factor $\mathrm{H}$ binding of monomeric $\mathrm{C}$-reactive protein downregulates proinflammatory activity and is impaired with at risk polymorphic CFH variants. Sci Rep (2016) 6:22889. doi:10.1038/srep22889 
91. Chirco KR, Whitmore SS, Wang K, Potempa LA, Halder JA, Stone EM, et al. Monomeric C-reactive protein and inflammation in age-related macular degeneration. J Pathol (2016) 240(2):173-83. doi:10.1002/path.4766

Conflict of Interest Statement: The authors declare that the research was con ducted in the absence of any commercial or financial relationships that could be construed as a potential conflict of interest.
Copyright (c) 2018 Molins, Romero-Vázquez, Fuentes-Prior, Adan and Dick. This is an open-access article distributed under the terms of the Creative Commons Attribution License (CC BY). The use, distribution or reproduction in other forums is permitted, provided the original author(s) and the copyright owner are credited and that the original publication in this journal is cited, in accordance with accepted academic practice. No use, distribution or reproduction is permitted which does not comply with these terms. 